\title{
Natural History of Diabetes
}

\section{Ciampolini $\mathbf{M}^{*}$}

Preventive Gastroenterology Unit, Department of Paediatrics, Università di Firenze, Italy

*Corresponding author: Mario Ciampolini, Preventive Gastroenterology Unit,

Editorial

Volume 2 Issue 5

Received Date: November 13, 2017

Published Date: December 11, 2017

Department of Paediatrics, Università di Firenze, Italy, E-mail: mlciampolini@fastwebnet.it

\section{Editorial}

This editorial is a response to many and many requests to submit a paper on diabetes although I never treated diabetes except for a few subjects. I treated many reversible pathological conditions by teaching a meal pattern prompted by demand (from children) or hunger perception from adults. Initially I recruited infants in the second year of life. Mothers of these infants wanted a different meal pattern for relapses of diarrhea, vomiting or anorexia. I taught a meal pattern based on demand by the infant [1-4]. The name of the novel way of eating was Initial Hunger Meal Pattern (IHMP) after arrival of adults who required treatment for functional disorders of the bowel or for body overweight [3]. A decrease of daily energy intake was soon ascertained together with a decrease in the weekly pre-prandial blood glucose (BG). Both were assessed by 7-d home diaries. The diaries combined the report of energy consumption per meal and the consequent BG at the end of inter-meal interval. Energy amount per meal was the bet that adults had to predict in order to arise three events of initial hunger (IH) per day and the pre-prandial measurement checked the bet energy amount [1-3].

Subjects learned to recognize IH by experiencing meal suspension for two or more hours. The diary reports were useful to better teach the new meal pattern. Children preferred a higher number of meals. The meal pattern of infants responded to three to six hunger arousals per day. Old people also accepted two meals per day. Energy administration and intake were proportionate to the time interval to be achieved before arousals of hunger perception or demand by the infant. The mother had to learn metabolic expenses of the child and the satiating power of food items through the day [4]. The constancy in composition of the first food, milk, produced an easy "colloquium" where maternal words were alternated with milk administration/intake. A quarter of an hour of one breast was often sufficient. The mother might add 5 minutes of the second breast, approximately. The one year old child's demand might consist in walking, crying, indicating, in a mood change or in searching for food. Each demand manifestation should appear in absence of food cues. Adults and infants showed that BG was constant at hunger perception: $\mathrm{BG}$ was $76.6 \pm 3.7 \mathrm{mg} / \mathrm{dL}$ [1-4]. Adults could notice mental or physical weakness instead of gastric pangs and the concomitant BG was similar [3]. Heavy physical work implied a higher BG in association with hunger arousal $[1,2]$. At recruitment, a third to a half investigated adults and children showed already a BG about $76.6 \mathrm{mg} / \mathrm{dL}$ [1]. This finding suggests that a consistent minority of children and adults approximately follow a BG estimation to predict energy needs and decide intake. This was shown by control subjects [3]. Mean preprandial BG in a week (MBG) decreased about $20 \%$, energy intake decreased by $20 \%-30 \%$ [1,2]. Also glycated hemoglobin decreased consistently and significantly. The list of decreases (effects) includes Resting Metabolic Rate by indirect calorimetry, Total Energy Expenditure by doubly labeled water and insulin resistance by glucose tolerance tests for about $15 \%-30 \%$ together with body weight decrease [1-7].

Body weight did not decrease in those who were both normal weight and insulin sensitive at recruitment $[1,4]$. These results correspond to homeostatic energy availability, to prevention of fattening, diabetes, to prevention of the associated vascular risks and to prevention of malignant diseases [7]. Members of the Study for Ingestive Behavior (SSIB) already questioned how trained subjects became able to predict BG. Homo sapiens are capable to recognize many more sensations than the well-known sensations obtained by 6 senses: sounds, rhythms, figures, abdominal pain, headache... Accurate estimation of current BG after training 


\section{Psychology \& Psychological Research International Journal}

demonstrated that children and adults learn sensations of current energy availability [3]. These recognition activities remained useless and neglected by mankind for long time until abundant food production. Unexplored sensations do not mean that hunger sensations do not exist or have to remain outside the realm of science, much more that the $\mathrm{IH}$ recognition curbed conditioned intake by an individual amount that was related to the energy intake and BG at recruitment [1-7].

The trained meal pattern significantly and largely decreased mean energy intake, pre-prandial Mean BG, glycated hemoglobin, insulin resistance at OGTT $[1,2,5,8]$, Resting Metabolic Rate by indirect calorimetry, Total Energy Expenditure by doubly labeled water and insulin resistance by glucose tolerance tests for about $15 \%-30 \%$ together with significant body weight decrease [1-6]. Body weight did not decrease in those who were both normal weight and insulin sensitive at recruitment. These results correspond to prevention of fattening, diabetes and associated vascular and malignant diseases [7]. Before diabetes development, conditioned intake promotes a $30 \%$ increase in insulin resistance, 15\% increase in resting metabolic rate, steatorrhea, slowing down of nutrient absorption, increased growth of few bacterial species that are immunogenic and a conspicuous increase in immune stimulation [8-19]. More than half immune cells reside in the mucosa of small intestine [9]. Functional alterations develop like headache, abdominal and joint pain. After decades of high immune stimulation, vascular risks and malignant diseases also arise [17].

These developments suggested already prevention. In the year 2012 we wrote: "Infants with relapsing diarrhea are more sensitive than other infants to a positive energy imbalance, eg, during scheduled meals, because they have lower production of insulin and thinner skin-folds. The choice between scheduled and requested meals may be a historical or fashion issue. In the first days of life, these two feeding options are equivalent, and are dictated by familial and medical customs, current local fashion, convenience, and also by a null hypothesis, which is wrong. Currently, a "crowd effect" by the general intake trend may nullify any intake education at an early age like in this report. Given the fact that part of the population maintains low pre-prandial blood glucose by free choice, given the demonstrated maintenance of requested meals up to 12 years of age, the equivalence of early instructions for new mothers, the habitual, persistent nature of mean blood glucose due to associated organic changes, and emphasizing better health in children and adults who maintain pre-prandial low blood glucose, a change in instructions on rearing seems obvious and mandatory from the neonatal days. This change might help many people to maintain low blood glucose levels. Preadolescents closely depend on conditioning but adolescents prefer a free choice in our investigations [20]. Adults are conditioned by social constraints and about $30 \%$ refuse to implement instructions. Acceptation of feeding by demand since new born days would be an important suggestion for all life.

We had the opportunity to follow two diabetic subjects 50 - 60 years of age old [20]. They followed a diet that was prescribed by dieticians of about $1200 \mathrm{kcal}$ per day and had reached the Body Mass Index (BMI) of 33 and 39. Both subjects showed no hunger arousal even after 48 hours of starvation, neither as gastric pangs nor as body or mental weakness. The first maintained a BG of 76 $\mathrm{mg} / \mathrm{dL}$ to $80 \mathrm{mg} / \mathrm{dL}$ during and after use of met for min, He stopped met for min and maintained an intake of 350 kcal per day; the second maintained a BG of $95 \mathrm{mg} / \mathrm{dL}$ with a similar intake for one year. Both decreased their body weight by $20 \%$ and $15 \%$ of initial weight and after this decrease had again hunger manifestations at a BG of about $76.6 \mathrm{mg} / \mathrm{dL}$. They had low energy intake and low BG and an important body weight decrease without complaining hunger or body and mental weakness until BG was again low. Maintenance of hunger manifestations appears to be important in prevention of diabetes. MBG passed from $79 \pm 2.0 \mathrm{mg} / \mathrm{dL}$ to $76.6 \pm 3.1 \mathrm{mg} / \mathrm{dL}$ and had events of IH. MBG in the second subject passed from 95.4 $\pm 12.2 \mathrm{mg} / \mathrm{dL}$ to $92.0 \pm 13.6 \mathrm{mg} / \mathrm{dL}$ after one year. Yet, the measurements before 7 dinners decreased to $75.3 \pm 5.1$ $\mathrm{mg} / \mathrm{dL}$ in association with hunger manifestations. We have too few data for conclusions. We may however suggest further research. Before treatment with antidiabetic drugs, assess MBG and IH arousals. It seems possible that diabetic people cannot decrease BG down to $76.6 \pm 3.7 \mathrm{mg} / \mathrm{dL}$ and have lost IH arousals. Moreover the two diabetic subjects inform us that energy intake may largely be reduced if we provide all essential minerals and vitamins. This energy poor provision consisted mainly in not starchy vegetables. Fruit could be added.

\section{Conclusion}

Current society promotes diabetes since the first newborn meals by food offering: scheduled meals are considered normal custom for educated societies. Infant/mother pairs recognize easily $\mathrm{IH}$ without BG measurements [5]. Adults can learn the recognition in few days, and meals allowing three IH arousals per day are associated with an even energy balance $[3,4]$. This meal pattern may become the reference for normal energy intake and for normal/ideal bodyweight. Repeating the 


\section{Psychology \& Psychological Research International Journal}

recognition of IH sensation after the first initial meal suspension requires, in adults, a validation by the preprandial measurement of BG. This measurement may be repeated after months and years to check the identity in recognition. Diabetics, old and overweight people with poor insulin production may not feel hunger at all.

\section{References}

1. Ciampolini M, Sifone M (2011) Differences in maintenance of mean Blood glucose (BG) and their association with response to "Recognizing Hunger". I J Gen Med 4: 403-412.

2. Ciampolini M (2001) Meal by meal dynamic balance of energy in blood. Research Signpost, 37/661(2), Vazhappalli Jn., Fort Post Office, Trivandrum-695 023, Kerala, INDIA 1-9.

3. Ciampolini M, Bianchi R (2006) Training to estimate blood glucose and to form associations with initial hunger. Nutr Metab (Lond) 3: 42.

4. Ciampolini M (2012) Requested meals versus scheduled meals. I J Gen Med 5: 345-353.

5. Ciampolini M, Brenna JT, Giannellini V, Bini S (2013) Interruption of scheduled, automatic feeding and reduction of excess energy intake in toddlers. Intern J Gen Med 6: 39-47.

6. Ciampolini M, Lovell-Smith D, Sifone M (2010) Sustained self-regulation of energy intake. Loss of weight in overweight subjects. Maintenance of weight in normal-weight subjects. Nutr Metab (Lond) 7: 1-4.

7. Gregg EW, Shaw JE (2017) Global Health Effects of Overweight and Obesity. The New England Journal of Medicine 377(1): 80-81.

8. Ciampolini M (2013) Interruption of automatic feeding, of fattening and associated immune deficiency. Recent Res Devel Nutrition 9: 1-31.

9. Mowat AM (1987) The cellular basis of gastrointestinal immunity. In: Marsh MN (Ed.) Immunopathology of the small intestine. John Wiley \& Sons, Chichester pp: 44.
10. Brandtzaeg P, Halstensen TS, Kett K, Krajci P, Kvale D, et al. (1989) Immunobiology and Immunopathology of Human Gut Mucosa: Humoral Immunity and Intraepithelial Lymphocytes. Gastroenterology 97(6): 1562-1584.

11. Abrams GD (1977) Microbial effects on mucosal structure and function. Am J Clin Nutr 30(11): 18801886.

12. Hungate RE (1967) Ruminal fermentation. In: Heidel W, Code CF, Handbook of Physiology, sect 6, Alimentary canal. Washington DC: Am Physiol Soc, pp: 2725-2746.

13. Ciampolini M, Bini S, Orsi A (1996) Microflora persistence on duodenojejunal flat or normal mucosa in time after a meal in children. Physiol Behav 60(6): 1551-1556.

14. Ciampolini M, Borselli L, Giannellini V (2000) Attention to Metabolic Hunger and Its Effects on Helicobacter Pylori Infection. Physiol Behav 70(3-4): 287-296.

15. Cooper IF, Siadaty MS (2014) 'Bacteriums' associated with 'Blood Glucose Level Finding'. Bio Med Lib Review.

16. Mccoy KD, Köller Y (2015) New developments providing mechanistic insight into the impact of the microbiota on allergic disease. Clin Immunology 159(2): 170-176.

17. Kristensen VN (2017) The antigenicity of the tumor cell. N Engl J Med 376(5): 491-493.

18. Kubes P, Meahl WZ (2012) Sterile Inflammation in the Liver. Gastroenterology 143(5): 1158-1172.

19. Lynch SV, Pedersen O (2016) The Human Intestinal Microbiome in Health and Disease. N Engl J Med 375(24): 2369-2379.

20. Ciampolini M, Cecchi G, Danti L (2017) A reproducible, subjective limit in energy intake. Medicinal Chemistry, Milano. 